\title{
熱伝導の分子動力学機構に関する研究*
}

\author{
渡辺章弘*1, 小竹進*2

\section{Study on Molecular Dynamics Mechanism of Heat Conduction}

\author{
Akihiro WATANABE and Susumu KOTAKE
}

\begin{abstract}
The molecular process of heat conduction is studied with the molecular dynamics method for Lennard-Jones potential solid atoms. The probability density of the heat flux and its two-point time and space correlations are investigated for an understanding of the transfer mechanism of heat energy on the molecular level. The heat flux in the direction of the temperature gradient has a larger probability for carrying the molecular energy toward the low-temperature side than that toward the high-temperature side. The spatial length of the heat flux correlation is about 4 or 5 times the lattice length. Lattice defects in the solid reduce the correlation of heat flux, whereas lattice particles having deeper potential wells yield a stronger correlation of heat fluxes.
\end{abstract}

Key Words: Heat Conduction, Molecular Dynamics, Heat Flux Correlation, Kinetics

\section{1. 緒言}

従来, 熱工学に限らず機械工学においては，その対 象が連続体であるとか, 準平衡であるとかという仮定 のもとにさまざまな現象が論じられてきた。しかし， 近年の著しい工業技術の進歩に伴い機械工学で扱う対 象とその条件も大きく変化し, 薄膜・微粒子技術, 半導 体技術，レーザ技術などの新しい分野では，寸法スケ ールは小さいが取扱うエネルギーレベルは大きくなっ ている，取扱う現象のスケールが大きくエネルギーが 小さいときは，物質を連続体として扱って現象を考え ることができたが，このようにスケールが小さくエネ ルギーが大きくなってくると，連続体として現象を考 えることが不可能になり，現象を分子・原子レベルで 考察することが必要となってくる(1).

熱工学においても, 薄膜熱伝導, 半導体基板への凝 縮・蒸着現象, レーザ加工における分子・原子の融解・ 蒸発，ふく射による熱伝達機構など分子・原子レベル での考察が必要であり，そのなかでエネルギーの輸送 過程として最も重要な現象である熱伝導も，分子・原

* 原稿受付 平成 5 年 4 月 1 日.

*1 学生員, 東京大学大学院（１13 東京都文京区本郷 7-3-1).

*2 if 冒, 東宗大学 T学部.
子の運動と結びつけてその本質を理解しなければなら ない.

このようなことから、ここでは固体物質における熱 伝導現象を分子・原子レベルで数值実験的研究を行い， 熱エネルギーの移動過程を調べた．熱伝導現象にも固 体金属のように自由電子による寄与がほとんどのもの から，絶縁体のように分子・原子の振動運動によるも のまでさまざまな現象であるが,ここではまずその最 初の研究として $\mathrm{Ar}$ のような単原子分子の絶縁体の熱 伝導の分子動力学機構の研究を行った，量子効果の影 響が小さいときは，分子・原子の運動をポテンシャル 場での質点の運動として記述することができ，その運 動方程式を数値計算することによって，分子・原子の 運動を求めることができる。この分子動力学法を用い て，個々の分子・原子がどのように熱エネルギーの移 動にかかわっているのかということと，その熱エネル ギー移動が各分子・原子間でどのような相関関係をも っているのかということを調べた。これらは各分子・ 原子(以下粒子という)の熱流束の確率密度分布，その 粒子間相互相関を求めることによって調べることがで きる、さらに、こうした熱エネルギ一移動の分子動力 学機構に関連して固体粒子構造がどのような影響をも つのか調べるために，格子欠陷や異粒子が存在する場 
合の熱伝導機構についても考察した。

\section{2. 固体粒子系と計算方法}

分子動力学的手法により熱伝導現象を計算するため に，図10ような固体粒子系を考える。ここでは熱伝 導の現象的理解を目的として Arのような単原子分子 の二次元分子粒子系を仮定する．粒子系は上下に 3 層 からなり上部から加熱層, 伝導層, 冷却層とし熱が図 10 上から下 $(y$ 方向)に伝わるものとする．膜の横方 向の広がりを考えるために, 左右境界 ( $x$ 方向)には周 期境界条件を用い，上下( $y$ 方向)には, 温度が均一に なる粒子層を設けて断熱境界条件を作り与える熱がす べて伝導層に流出入するように考慮した。

熱伝導の数値計算においては，一定温度差のもとで 熱流束を計算する万法と一定熱流束のもとで温度差を 計算する方法(2) とがあるが，ここでは境界条件や熱流 束の安定性から温度差を一定にする手法をとる。

粒子間にはVan der Waalsポテンシャルとして126 Lennard-Jones 形の二体ポテンシャルを考える。こ のとき粒子の運動は次の Nowton方程式で表され, この式を数值計算することによって時間ごとの各粒子 の速度, 位置が求まる(1).

$$
\begin{aligned}
& m \frac{d^{2} \vec{x}_{i}}{d t^{2}}=\sum_{j}\left(-\nabla \Phi_{i j}\right) \cdots \\
& \Phi_{i j}=4 \varepsilon\left\{\left(\frac{\sigma}{r_{i j}}\right)^{12}-\left(\frac{\sigma}{r_{i j}}\right)^{6}\right\}
\end{aligned}
$$

ここで, $m$ は粒子の質量, $\vec{x}_{i}$ は粒子 $i$ の座標, $\Phi_{i j}$ は 粒子 $i, j$ 間のポテンシャル, $r_{i j}=\left|\vec{x}_{j}-\vec{x}_{i}\right|$ である.

上下層に温度差を与え, 平衡状態に達してから各粒 子の熱流束の確率密度分布, 時空間的な相関を求め, 熱エネルギーの分子レベルでの輸送過程を調べた。さ らに、これらの熱伝導の分子機構が固体粒子構造でど

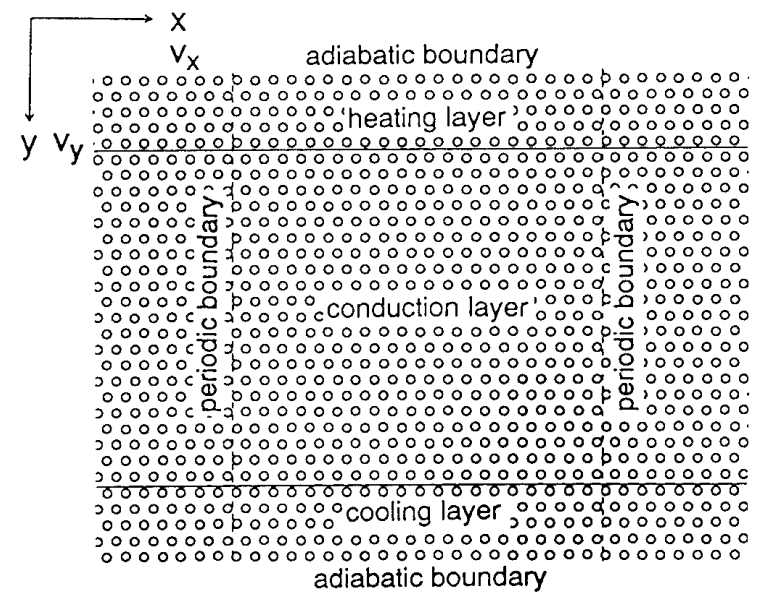

図 1 固体粒子系
のように変化するかを調べるために，固体粒子のポテ ンシャルパラメータを変化することにより, 格子欠宿 や異粒子を含を固体粒子構造について同様な熱エネル ギー輸送過程を調べた。

物理量は結果に一般性をもたせるために次のように 位置 $x$, 時間 $t$, ポテンシャルエネルギー $\Phi$, 温度 $T$ を無次元化して計算を行った。

$$
\left.\begin{array}{c}
\frac{\vec{x}}{\sigma} \rightarrow \vec{x}, \frac{t}{\sigma \sqrt{m /(24 \varepsilon)}} \rightarrow t \\
\frac{\Phi}{24 \varepsilon} \rightarrow \Phi, \frac{T}{24 \varepsilon / k} \rightarrow T
\end{array}\right\}
$$

熱平衡での系平均温度は $T=0.007(20 \mathrm{~K})$, 上下温度 差は $\Delta T=0.003(9 \mathrm{~K})$ を代表例として多くの計算を行 った [( )内の值は $\mathrm{Ar}$ 換算値 $]$ 。また粒子数は横方向 20 個, 伝導層 21 層, 加熱層 5 層, 冷却層 5 層であり, このときの数值計算の時間刻み $\Delta t$ は無次元時間で 0.01 で十分であるが，これは Ar 換算時間で約 5 fs に 相当し粒子の振動の約 $1 / 250$ 周期に当たる.

\section{3. 計算結果と考察}

粒子 $i\left(\right.$ 位置 $\left.\vec{x}_{i}\right)$ ) $\vec{n}$ 方向への熱流束 $q_{i, n}(t)$ は, 工 ネルギーを $e_{i}$, 粒子速度を $\vec{v}_{i}$ とするとき

$$
\begin{aligned}
& q_{i, n}(t)=\left(\vec{v}_{i} \cdot \vec{n}\right) e_{i} \\
& e_{i}=\frac{1}{2} m \vec{v}_{i}^{2}+\sum_{j} \Phi_{i j} \equiv e^{(k)}+e^{(p)}
\end{aligned}
$$

と表せる(1). 粒子iのエネルギー $e_{i}$ は, 運動エネルギ 一 $e^{(k)}$ とポテンシャルエネルギー $e^{(p)}$ の和である。 $y$ 方向の $q_{i, y}(t)$ を $e_{i}(t), \vec{v}_{i, y}(t)$ とともに示すと図 2 の ようになり，時間的に大きく振動し，この振幅は温度 とともに増加する。

$3 \cdot 1$ 熱流束の確率密度分布各粒子の熱流束 $q_{i}(t)$ の時間平均熱流束 $\bar{q}_{i}$ の確率密度分布

$$
P\left(\bar{q}_{i}\right)=\frac{N\left(\bar{q}_{i}-\Delta q<\bar{q}_{i}<\bar{q}_{i}+\Delta q\right)}{N\left(-\infty<\bar{q}_{i}<+\infty\right)}
$$

を図 3 に示す。ここで $N$ 㹥 $\left(\bar{q}_{i}-\Delta q\right)$ と $\left(\bar{q}_{i}+\Delta q\right)$ の

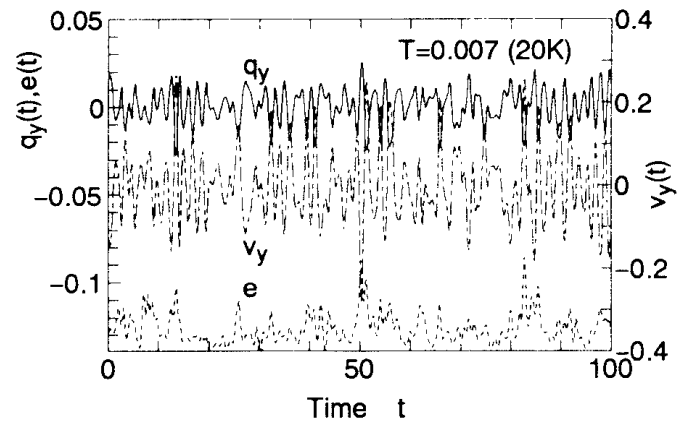

図 21 粒子の熱流束・速度・エネルギーの時間変化 $\left[-: q_{y}(t),-----: v_{y}(t),-\cdots--e(t)\right]$ 
間の熱流束值をもつ粒子の数である．縦軸にその全粒 子に対する割合すなわち，確率密度分布 $P$ をとり，横 軸は各粒子のもつ熱流束を時間平均した值 $\bar{q}_{i}\left(\bar{q}_{x}: x\right.$ 方向, $\bar{q}_{y}: y$ 方向)を示し, 高温側から低温側に向か う場合を正にとってある， $x$ 方向熱流束の総和は零で あるが, $y$ 方向熱流束は平均すると正の值をとるが低 温＼cjkstart高温の熱流束の確率もあることがわかる．また系 温度が高い場合についての結果を同様に $y$ 方向につ いてのみ示したのが図 4 である. 図 4 から, 系温度が 高いと確率密度分布は横に広がった分布をするように なる。また，逆に系温度が低いと狭いとがった分布を する.

さらに熱流束の詳しい挙動を調べるために，熱流束 が $y$ 方向正負に流れる場合を区別して時間平均工ネ ルギー $\bar{e}_{i}$, および時間平均速度 $\bar{v}_{i}$ の同様な確率密度 分布

$$
\begin{aligned}
& P\left(\bar{e}_{i}\right)=\frac{N\left(\bar{e}_{i}-\Delta e<\bar{e}_{i}<\bar{e}_{i}+\Delta e\right)}{N\left(-\infty<\bar{e}_{i}<+\infty\right)} \\
& P\left(\bar{v}_{i}\right)=\frac{N\left(\bar{v}_{i}-\Delta v<\bar{v}_{i}<\bar{v}_{i}+\Delta v\right)}{N\left(-\infty<\bar{v}_{i}<+\infty\right)}
\end{aligned}
$$

を示すと図 5,6 のようになる。これによるとエネルギ 一はポテンシャル，運動エネルギーともに熱流束と同 じような分布を示し総和が正の值をとっているが，速 度の総和は $x$ 方向, $y$ 方向ともに当然零になってい る.つまり $v_{y}$ の総和は零であるが, $v_{y}^{2}$ の総和は零にな

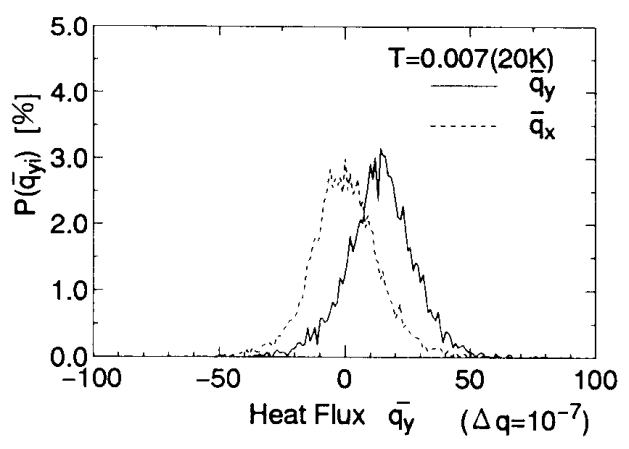

図 3 熱流束の時間平均確率密度分布 $(20 \mathrm{~K})$

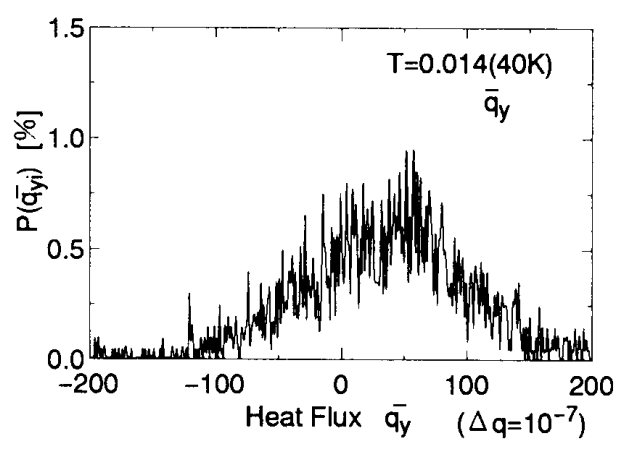

図 4 熱流束の時間平均確率密度分布 $(40 \mathrm{~K})$
らない.これらの結果から, 固体粒子は $y$ 方向の運動 によって高いエネルギーを速く低温側へ運び, 低いエ ネルギーをゆっくりと高温側へ運ぶ熱エネルギー輸送 を行っていることがわかる。

この考察をさらに確認するために, $v_{y}$ の正負方向 でのエネルギーの瞬間確率密度分布の差を調べた。図 7 に運動エネルギーについて図 8 にポテンシャルエネ ルギーについてその結果を示す．横軸はエネルギーの 大きさを, 縦軸はそのエネルギーをもつ粒子で $v_{y}$ が 正方向と負方向の粒子数の差を示している，つまり， 横軸のあるエネルギーに対してそれが正の值を示すと きは，そのエネルギーをもつ粒子の数は $y$ の正方向に 運動しているものの数が多く, 負の值を示すときは, 負方向に運動しているものの数が多いことを示す. 図 7,8 から，低いエネルギーをもつ粒子は負の方向に運 動しているものが多く, 高いエネルギーをもつ粒子は 正の方向に運動しているものが多いことがわかる.

\section{$3 \cdot 2$ 熱流束の粒子間相互相関 粒子間を熱がど} のように伝わるのか調べるために 2 粒子 $\left(x_{0}, x_{i}\right)$ 間で の熱流束の空間相関

$$
Q_{y i}(\tau)=\lim _{T \rightarrow \infty} \frac{1}{T} \int_{-T / 2}^{T / 2} q_{y}\left(t ; \vec{x}_{0}\right) \cdot q_{y}\left(t+\tau ; \vec{x}_{i}\right) d t
$$

を調べた. その結果の例を図 9 に示す。ここで $i$ は図

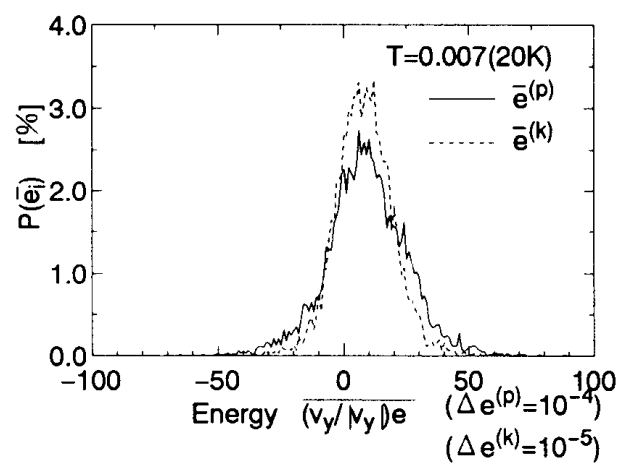

図 5 エネルギーの時間平均確率密度分布

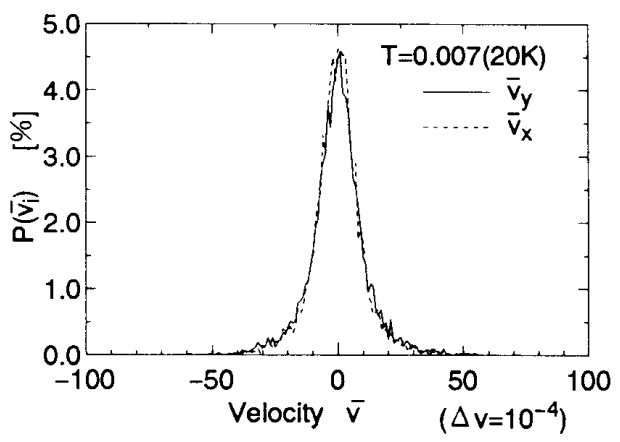

図 6 速度の時間平均確率密度分布 
10 中の粒子番号を表す. 図 9 から粒子間の距離が遠く になるにつれて相関が減衰していくのがわかる。この ような相関を多くの粒子間で求め, その相関強さの最 大值分布を図 10 (表 1)に，そのときの時間遅れ分布を 図 11(表 2 )に示す.ここで円が大きいほど相関が強く， 相関が最大となる時間遅れが短い。これらの結果から 次のことがわかる．各粒子間の熱流束相関は熱流束方 向にはほほ上下対称であり，近傍粒子と強い相関を示 すが距離とともに急速に減衰する。そして粒子約 5 層 分まで相関をもっている，また，熱流束と垂直方向に は相関そのものは小さいが, 距離に対する相関の減衰 割合が小さく，時間遅れも大きい傾向にある。

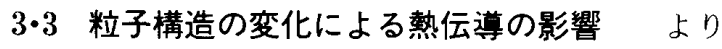
実際的な熱伝導現象を理解するためには，これまでの ような整然と粒子が並んだ構造をしている粒子系だけ でなく，格子欠陥や不純物等を含んだ構造を考えなけ ればならない。そのために, 固体粒子の構造の変化に より上述の熱伝導機構がどう変化するかを, 最も極端 な例として格子贿を含む場合と異粒子を含む場合に ついて調べた。まず格子欠陥を含む場合について，熱 流束の空間相関を図 12 に，それから求めた相関強さ の最大值分布を図 13(表 1) に，そのときの時間遅れ分 布を図 14 (表 2) に示す. 格子久陥があると, 格子久陷 の存在により上下左右非対称になり, そのすぐ近傍で

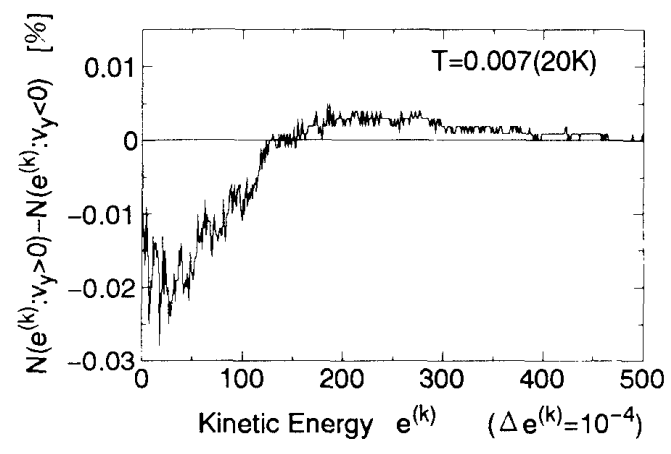

図 7 エネルギーの瞬間確率密度分布の差 (運動エネルギー)

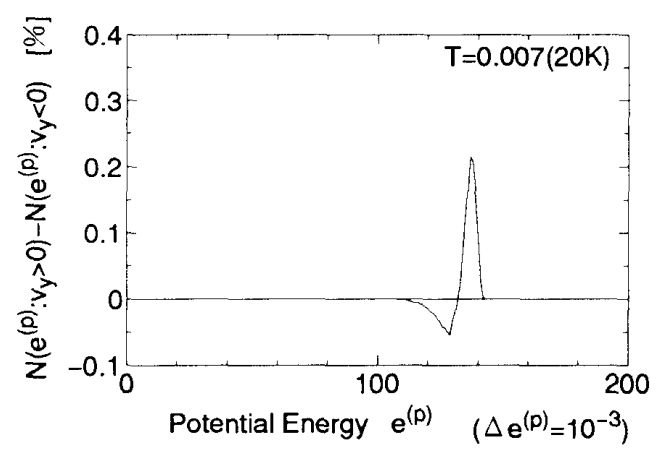

図 8 エネルギーの瞬間確率密度分布の差 (ポテンシャルエネルギー)
は相関が著しく弱くなり，熱流束は欠陌格子の分だけ 欠如されるような流れになることがわかる。しかし， このような欠楩の影響は多くとも粒子 2 亿個分まで でそれ以上では影響を受けない.

次に，格子欠宿の代わりにある種の異粒子を置くこ とにより相関がどのように変化するかを調べた。ここ では，異粒子としてポテンシャル係数である $\varepsilon$ を変え た粒子 $(\varepsilon=10)$ を上述の格子欠陥の場所に配置して同 様の熱流束の空間相関を求めたのが図 15 である。ま た，それから求めた相関強さの最大值分布を図 16(表 1)に，そのときの時間遅れ分布を図 17 (表 2 )に示す。 異粒子を置くことにより欠宿の場合とは逆に異粒子側 の相関を強くすることができ，熱流束をそこに収れん

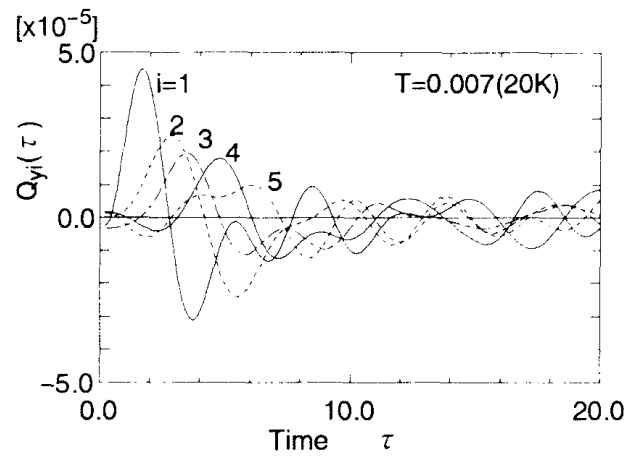

図 9 熱流束の粒子間相互相関

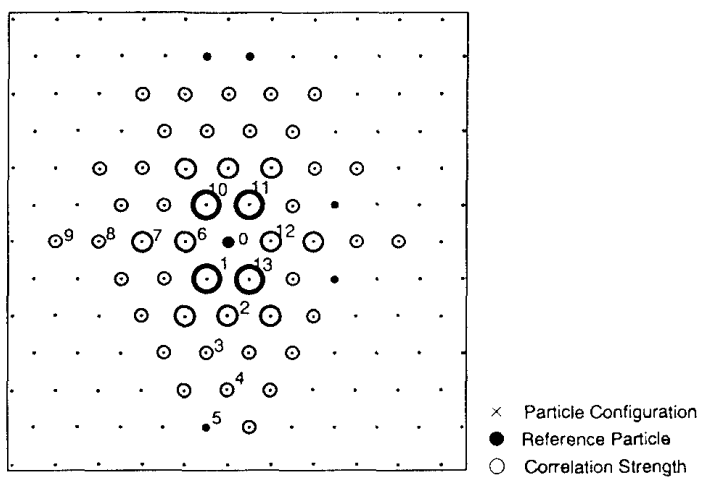

図 10 熱流束の相互相関強さ分布

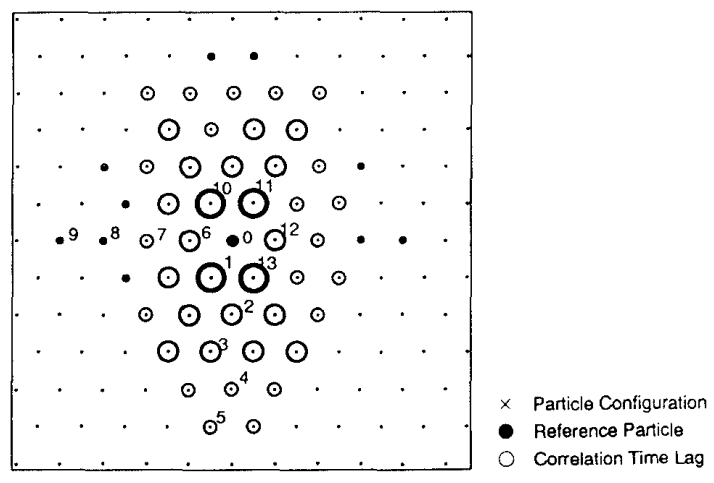

図 11 熱流束の相互相関時間遅れ分布 
表 1 相互相関強さ $\left(\times 10^{-5}\right)$

\begin{tabular}{l|c|c|c|c|c|c|c}
\hline $\begin{array}{l}\text { pair } \\
\text { particle } \\
(0-\mathrm{i})\end{array}$ & 10 & 11 & 1 & 13 & 6 & 12 & 2 \\
\hline Fig. 10 & 4.1 & 4.5 & 4.2 & 4.3 & 2.4 & 2.6 & 2.6 \\
\hline Fig. 13 & 4.2 & 3.9 & 4.2 & - & 3.0 & 1.0 & 1.0 \\
\hline-1.5 & 5.9 & 6.8 & 9.4 & 28.8 & 4.5 & 6.5 & 6.8 \\
\hline
\end{tabular}

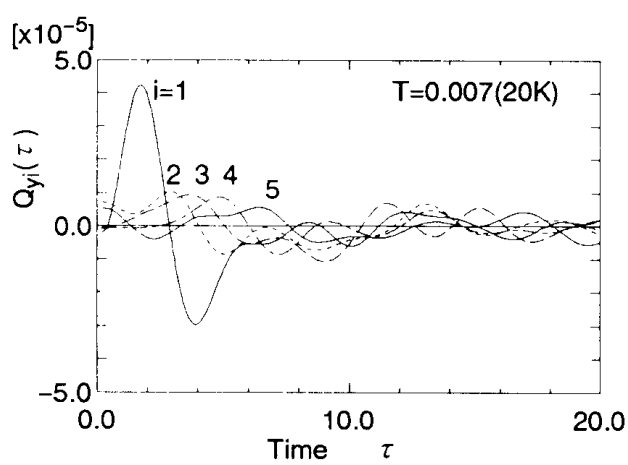

図 12 格子欠陌がある場合の熱流束の粒子間相互相関

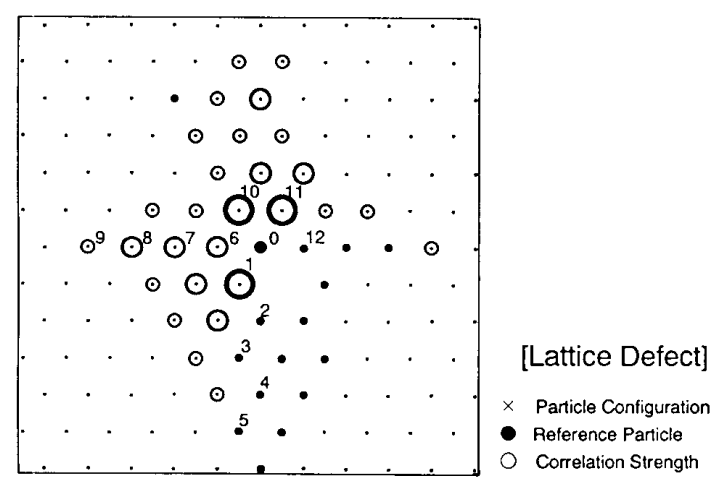

図 13 格子欠楩がある場合の熱流束の相互相関強さ分布

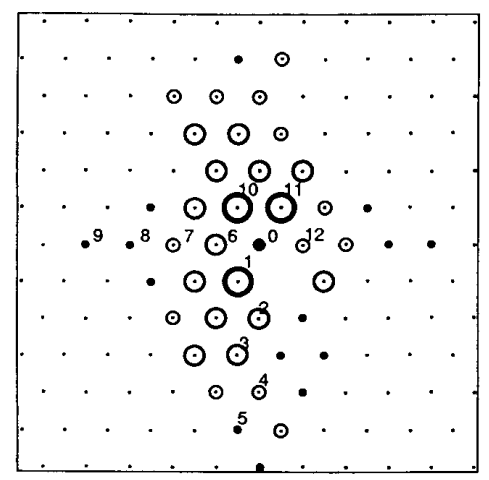

$\begin{aligned} & \text { [Lattice Defect] } \\ & \times \text { Particle Configuration } \\ & \text { - Reference Particle } \\ & 0 \text { Correlation Tima Lag }\end{aligned}$

図 14 格子尔楩がある場合の熱流束の相互相関時間遅れ 分布
表 2 相互相関時間遅れ

\begin{tabular}{l|c|c|c|c|c|c|c}
\hline $\begin{array}{l}\text { pair } \\
\text { particle } \\
(0-\mathrm{i})\end{array}$ & 10 & 11 & 1 & 13 & 6 & 12 & 2 \\
\hline Fig. 11 & 1.6 & 1.6 & 1.6 & 1.6 & 2.8 & 2.8 & 2.6 \\
\hline Fig. 14 & 1.8 & 1.8 & 1.8 & - & 3.0 & 4.4 & 3.0 \\
\hline Fig. 17 & 1.6 & 1.6 & 1.6 & 1.2 & 3.0 & 2.2 & 2.2 \\
\hline
\end{tabular}

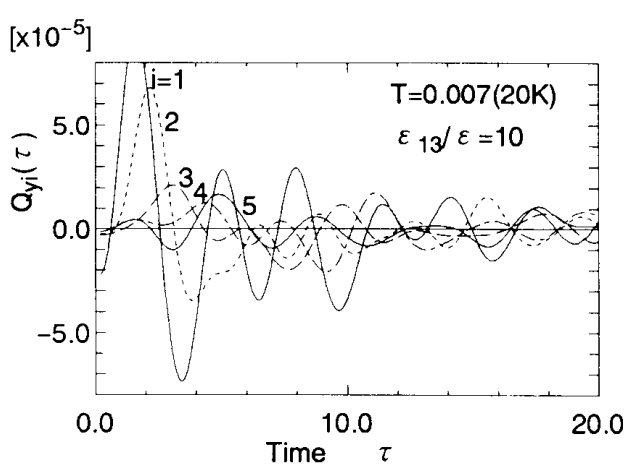

図 15 異粒子がある場合の熱流束の粒子間相互相関

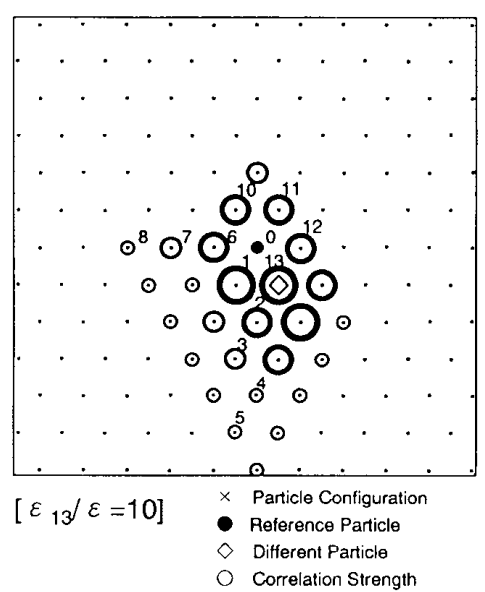

図 16 異粒子がある場合の熱流束の相互相関強さ分布

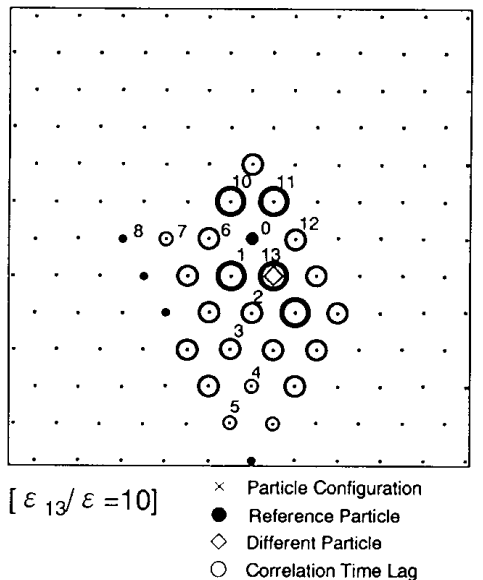

図 17 異粒子がある場合の熱流束の相互相関時間 遅九分布 
させる働きをすることがわかった。またその影響は欠 楩のときと同侎粒子 $2 \sim 3$ 個分である。

\section{4. 結 論}

固体物質における電子熱運動を伴わない熱伝導現象 について, 分子動力学的手法を用いて数值実験的に研 究し, 熱エネルギーの分子間の移動過程を調べた。そ のために熱流束の確率密度分布, 熱流束の粒子間相互 相関, 格子構造の変化による熱伝導の影響について調 ベ,以下のような結論がえられた。

（1）分子・原子の粒子単位で山温度こう配の正, 負どちらの方向にもエネルギーを運ぶが，その確率分 布の総和である粒子系全体の平均としては低温度方向 に熱が移動している。

（2）系平均温度が高いほど各粒子がとりうる熱流 束は幅広い分布を示す。

（3）個々の原子・分子の熱エネルギーを運ぶ方法 は高温側から低温側へ運ぶときは高いエネルギーを速 く運び, 低温側から高温側へ運ぶときは, 低いエネル
ギーをゆっくりと運ぶ.

（4）各分子・原子間でみてみると, 各粒子の熱流 束は温度こう配方向には約 5 層分まで相関をもってい 3.

（5）それらの相関は温度こう配方向には近傍粒子 と強い相関を示すが距離とともに急速に減衰する．温 度こう配と垂直方向では距離に対する相関は小さいが その滅衰割合が小さく，時間遅れは大きくなる傾向に ある。

（6）格子構造を変化させた場合として, 格子欠陥 がある場合には，熱流束の相互相関はその近傍で著し く弱くなり，その影響は粒子 2〜3 個である.

（7）異粒子を混入させると欠宿のときとは逆にそ の粒子付近の相関が強くなる。

\section{文献}

（1）小竹, 分子熱流体，(1990)，107-114，丸善.

(2) Wakuri, S. and Kotake, S., Proc. ASME-JSME Thermal Eng. Joint Conf., 4 (1991), 33-40. 